\title{
STRUCTURING A COMPETENCY REPOSITORY - APPLICATION TO THE DOMAIN OF INFORMATION SYSTEMS
}

\author{
Ahmed Bounekkar ${ }^{1}$, Corine Cauvet ${ }^{2}$, Cyrille Desmoulins ${ }^{3}$, Daniel Marquie ${ }^{4}$, Michel Schneider $^{5}$, \\ Carine Souveyet ${ }^{6}$ and Cédric Teyssie ${ }^{4}$ \\ ${ }^{1}$ Université de Lyon, France \\ ${ }^{2}$ Université d'Aix-Marseille, France \\ ${ }^{3}$ Université Grenoble Alpes, CNRS, Grenoble INP, France \\ ${ }^{4}$ Université de Toulouse, France \\ ${ }^{5}$ Université de Clermont Auvergne, France \\ ${ }^{6}$ Université de Paris 1 Panthéon Sorbonne, France
}

\begin{abstract}
In this paper, we propose a method for structuring a competency repository based on 5 principles. Two of them consist in using a composition relation to define competencies at several levels of abstraction and a prerequisite relation to establish prerequisites between competencies. To illustrate the contributions of these principles, an application in the domain of information systems design and implementation is fully developed. This application is based on the discussions that were carried out within the "Competency Working Group" of the French network of MIAGE (Méthodes Informatiques Appliquées à la Gestion des Entreprises) Masters and within the framework of the IDEFI-N OPENMIAGE project funded by the French ANR (Agence Nationale de la Recherche). The proposed repository, in addition to a new structure, incorporates new competencies compared to existing repositories, in particular with regard to strategic management of the IS, development techniques, interpersonal competencies, prerequisites coming from basic disciplines. This repository aims primarily to help the organization of academic and professional training and to allow the assessment of personal skills.
\end{abstract}

\section{KEYWORDS}

Competency, Repository, Composition Relationship, Prerequisite Relationship, Information System, Learning Outcome

\section{INTRODUCTION}

The usefulness of a competency-based approach is now well recognized both in the professional world to characterize activities and help recruiting, and in the academic world to characterize educational objectives and help organizing training. The term competency refers to a complex concept covering different points of view and whose precise definition remains controversial. Recall that the most common acceptance distinguishes three inseparable components in a competency: knowledge, know-how, interpersonal competency. Furthermore, a competency can only be understood in relation to the context in which it is considered. In the professional world, it is know-how and interpersonal competencies that are highlighted while academics focus primarily on knowledge and reasoning.

Competency repositories have been developed in various fields. A repository can be structured in various ways. A structure can be characterized by three main criteria: i) the way in which competencies are divided into groups and possibly sub-groups; ii) the way in which the links between competencies are expressed within a group or between groups; iii) the level of detail with which competencies are expressed. It is clear that the more detailed the competencies are, the greater the volume of specifications is and the greater the need for adequate structuring is.

The structuring directly impacts the ease of use of the repository. Several types of users are concerned (repository designer, human resources manager, recruiter, teacher and trainer, student and listener) and their needs are different. But the ease of locating a competency in the repository and positioning it in relation to close competencies or prerequisites interests all users. 
Our objective in this paper is to show how the use of several principles can help improve the structuring of a competency repository and consequently facilitate its use. More specifically, we want to facilitate the following activities: searching for a competency in the repository, inserting a new competency, developing initial and vocational training, developing competencies assessments, searching for training to meet a learning objective.

We first establish a state of the art to identify different forms for structuring a competency repository. We then explain our five principles and discuss their impact on structuring. We then apply these principles to structure a competency repository in the domain of information systems design and implementation. The starting point of this application is the MIAGE repository, developed by the "competency working group" of the MIAGE Masters network. We suggest another structuring of this repository and we show how useful extensions can be inserted.

\section{STATE OF THE ART}

We first study the structuring of three competency repositories in the field of information systems. However, competencies are generally derived from typical activities of the domain and it is useful to also focus on the structuring of trade repositories. Finally, we mention some works that have addressed the study of relationships between competencies.

Competency repositories in the IS domain

We analyse hereafter three competency repositories: the e-CF (European e-Competence Framework) (e-CF, 2019), the MSIS (Master of Science Information Systems) (Topi, 2016), and the SFIA (Sfia, 2018).

The e-CF repository has been developed by the CEN (European Committee for Standardization). It consists of 40 competencies grouped into 5 main types of activities (Plan, Develop, Use, Facilitate, Manage). Each competency is defined globally by general activities denominated through action verbs. Five competency levels are considered. Each competency is associated with examples of know-how and knowledge. The e-CF does not include any explicit interpersonal competencies. It has a fairly general aim. It can be used both to characterize business activities and training objectives.

The MSIS repository, which is more precisely titled "Global Competency Model for Graduate Degree Programs in Information Systems", was developed under the aegis of the Association for Information Systems (AIS) and the Association for Computing Machinery (ACM). It was specifically designed for a Master degree in information systems. It covers the topics of information technology and information systems management. It is divided into five main sectors: Pre-Master Competencies; Information Systems Competencies; Domain Competencies such as management, law, health; Specialized Competencies and Individual Foundational Competencies. The Information Systems Competencies sector is itself divided into nine areas, one relating to ethics and sustainability issues and another relating to innovation and entrepreneurship. In each of these areas, competencies are specified at two levels of abstraction: the first level for categories and the second level for examples. Each of these levels is described with sentences using action verbs (in the infinitive for categories, in the present imperative for examples) and represent an activity.

The SFIA repository, in version 7, focuses on information and communication technologies, digital transformations and software engineering. It describes 95 professional competencies, which are organized into 6 categories and 17 sub-categories. Each competency is defined in the form of responsibility levels (up to seven levels are possible). These levels are characterized by five attributes (Autonomy, Influence, Complexity, Knowledge and Business Competencies).

We can see that the organization of these three repositories is presented in an ad-hoc hierarchical form. We can consider that this hierarchy implicitly underlies a composition.

The "Competency Working Group" of the French MIAGE network has also elaborated a version V0 for a competency repository in the domain of information systems. Its objective is to offer a competencies booklet to streamline the development of training. This booklet has also an ad-hoc hierarchical organization. It is in the form of teaching topics (TT) which are organized into 6 areas. Each topic is divided into LU (Learning Unit) and each LU is characterized by a set of ELO (Expected Learning Outcomes). An ELO specifies the objectives to be achieved through action verbs using the BLOOM classification (Bloom, 1956; Churches, 2008). ELO are then distributed according to a three-level classification. Each MIAGE Master training can be positioned in relation to this booklet to identify any adaptation to be made in order to meet the trade needs. 
Trade repositories in the IS domain

Many organizations have developed repositories to describe the objectives of trades related to information systems and the corresponding activities. At the European level, CEN has proposed a repository for trades and more recently a repository for roles (Cen, 2018). A role is a coherent set of activities. A role can be part of a trade. In France, the CIGREF repository (Cigref, 2018) is the best known and most often referenced. Other French organizations have also published professional repositories in the information systems domain, notably the OPIIEC (Opiiec, 2018) and the ANAP (Anap, 2020). The ANAP repository is targeted at health information systems. All these repositories have roughly the same sections for each profession: mission, typical activities, expected competencies, required training, deliverables and potential developments.

These repositories organize trades into families. Thus, the CEN repository is organized into 7 families and that of CIGREF into 9 families. In both cases, these families correspond roughly to a breakdown of activities into major processes. This type of organization can be a way to organize a competency repository.

The O*NET database (O*NET On Line, 2020) is an important initiative that brings together more than 1,000 trades covering the entire US economy. For each trade, it provides information on the following attributes: Tasks, Technology competencies, Knowledge, Competencies, Abilities, Work activities, Detailed work activities, Work context, Job zone, Education. ICT and information systems professions are well represented.

Competency repositories in other domains

Competency repositories have been proposed in many domains. Here are references to some of them: (Embo \& all, 2015; Lundqvist \& all, 2008; Sastre-Fullana \& all, 2014; Vandeweerd \& all, 2014; Whitehead \& Kuper, 2015). In a same domain, particularly in the medical domain, propositions can be multiple, overlapping, and heterogeneous. The idea of reconciling points of view is now often expressed.

Conceptual models of competencies relationships

Several works have been interested in the conceptual modeling of competencies with various objectives. For example, in (Schmidt \& Kunzmann, 2006) and (Paquette, 2006), ontologies are proposed, one for human resource management and the other to support e-learning systems. Relationships between competencies have been highlighted, particularly prerequisite, composition and subsumption relationships.

Either composition or subsumption relationships can be useful for organizing a competency repository by showing competencies at multiple levels of abstraction in hierarchical form.

We propose to use the composition relation to remain consistent with the implicit structuring of existing repositories in the IS domain. The novelty we introduce is that all hierarchical levels are expressed in a uniform way. We associate it with the prerequisite relationship. These two relationships constitute two of the principles of our proposal which also includes three other principles. We explain these five principles in the next section.

\section{STRUCTURING PRINCIPLES}

In this section, we present the five principles we propose for structuring a competency repository.

\section{Principle 1: Identification of competencies from trade activities}

An activity in a trade implies a competency for its good realization. This competency must then be characterized. It is generally a know-how. It can also be knowledge or interpersonal competencies. The context can be specified if necessary. It is important to note that, from the same activity, one or more know-how, knowledge and interpersonal competencies can be extracted simultaneously. It depends on the context in which this activity is expressed. Consider, for example, the "Analysing Needs" activity that can be found in the description of the business analyst job. This sentence induces a know-how which is associated with knowledge (knows the procedures to analyze needs, knows the different types of needs) and interpersonal competencies (has the qualities to dialogue with users, to lead a meeting, to write a report). The attitude of analyzing business activities to elicit competencies is natural and therefore general. The main problem is to select and organize them. Principles 2 to 5 defined below contribute to this essential task.

\section{Principle 2: Hierarchical organization by a composition relationship}

We suggest using the composition relationship to organize competencies at different levels of abstraction. The semantic interpretation of a composite competency is then obtained from its component competencies. 
This relationship induces a hierarchy insofar as a component competency can itself be the subject of a composition. However, we impose a weak unshared composition to mean that the deletion of a composite does not entail that of its components and that a component is linked to only one composite. We can then consider that this relation introduces a kind of semantic map.

We propose a hierarchical organization on four levels: general, main, specific, elementary.

The general level corresponds to very broad competencies for the domain (this level, for example, correspond to the main types of activity for the e-CF repository). The main level corresponds to the major competencies of the repository (this level could for example correspond to the 40 competencies of the e-CF repository). The specific level corresponds to an interpretation of the main level. The elementary level corresponds to the lowest level. The word elementary is used here to mean that it is no longer useful to decompose again. We will see that a specification at the elementary level contains all the ingredients to characterize the underlying learnings and their assessments.

The general, main and elementary levels are mandatory. The specific level is optional. Indeed, in some cases, the number of elementary competencies for a main competency may not be very large and the introduction of specific competencies is not necessary for the interpretation of the main competency.

This composition relationship and the resulting hierarchical organization are important for assessing the achievement of objectives. At the elementary level, the specification must make it possible to deduce unequivocally the test or tests to be performed (with the learner or with a job candidate) to assess the satisfaction of the competency.

Principle 3: Expression of the ability level by the use of action verbs respecting the BLOOM classification

The notion of LO (Learning Outcome) or ELO (Expected Learning Outcome) has been widely explored to describe training objectives, competencies and results. Universities, especially North American universities, have become accustomed to characterizing their training by LO which can be placed at the level of a course or at the level of a module. The ACM also defines its curricula using LO (Acm, 2016).

An effective solution for specifying LO is to use the classification of BLOOM and its associated action verbs (Bloom, 1956; Churches, 2008). Recall that the original BLOOM classification distinguishes six cognitive levels ranging from memorization to synthesis. This initial classification was the subject of several variants. Various studies have worked on how to express LO from action verbs corresponding to the BLOOM classification (Kennedy, 2006; Oster \& Tiu, 2008). A LO normally includes the following elements: an action verb, the object and conditions of this action, an element to allow the assessment of the ability to perform this action.

With action verbs respecting the BLOOM classification, we can express levels of ability to be achieved for know-how, knowledge and interpersonal competencies. Here are some examples:

- "Collecting the needs": know-how at ability level 3, assessed through observations in real or simulated conditions;

- "Describing the different types of needs": knowledge at ability level 1, assessed by oral or written tests;

- "Communicating in a professional environment": interpersonal competency at ability level 3, assessed through observations in real or simulated conditions.

In the three cases, the context is implicitly the company information system and the parties concerned are the users of the system.

We propose to extend the use of action verbs respecting the BLOOM classification to characterize the competencies of the four levels (general, main, specific, elementary).

It is clear that the verbs used in the different levels of a hierarchy must be specified consistently: the competency level of a compound competency must be in coherence with the levels of its component competencies.

It is important to note that action verbs respecting the BLOOM classification correspond to action verbs of the cognitive type. Affective or psychomotor action verbs have also been proposed and can be used as far as an assessment is possible.

\section{Principle 4: Choice of general competencies}

General competencies constitute the roots of the hierarchical organization and will directly condition the structure of the repository. They should therefore be chosen with care according to the objectives sought. This choice obviously depends on the domain covered, which must be defined beforehand. Many approaches can be considered to guide this choice: respecting the major processes that govern the domain, adapting trade 
classes in the domain, using cognitive classes (case of the e-CF repository), reusing the division of the domain into sectors of training.

This notion of general competency must be compared with the notion of block of competencies. In the French context, training and certification bodies are strongly encouraged to define blocks of competencies. In the labor code, a block of competencies is defined as a "homogeneous and coherent set of competencies contributing to the independent exercise of a professional activity and which can be assessed and validated". It is the respect of principles 2 and 3 which makes it possible to guarantee that a general competency can be considered as a block of competencies.

One wonders if more restrictive properties should be assigned to these blocks (and therefore to general competencies). For example, a form of semantic independence between blocks could make it easier to read, delete and add competencies to the repository. The use of a weak non-shared composition to organize hierarchy goes in the direction of this semantic independence.

We may need two different types of general competencies: superior competencies which are in direct correspondence with the activities of the trades in the domain; primary competencies which serve as support for the previous ones. These are necessary to acquire superior competencies, but they are not necessarily specified through an activity of a trade.

\section{Principle 5: Explicit representation of prerequisites}

In a competency repository covering a wide area, there are generally prerequisites between competencies. It is important to explain the most significant prerequisites. They will be very useful, for example, to an employee who would like to master a given competency; its prerequisites indicate the most efficient way to that aim, given the competencies already acquired. They will also be useful for a training manager who would like to design training that must include some competencies; the prerequisites help him to elaborate a complete and coherent set of training actions.

We wish to give flexibility to this relation. First, some prerequisites are obvious and there is no need to explain them. In addition, the number of competencies being able to be high, in particular at the elementary level, it would be tedious to make a complete explanation of it. We therefore propose to define explicit prerequisites only between the competencies of the first three levels (general, main, specific).

To allow instantiation of the prerequisites, it will be necessary to identify the competencies with labels.

\section{APPLICATION TO THE DOMAIN OF INFORMATION SYSTEMS}

In this section, we propose to apply the principles defined above to structure a competency repository in the domain of information systems design and implementation. The trades can be found in the CIGREF and CEN repositories. This competency repository is a priori oriented towards Master training: the competencies are those that a Bachelor or Master graduate should assess from his/her training. But this repository must also be able to allow a professional to position his competencies and determine ways of progression. We want to cover all the competencies in the domain and thus objectify all the variants of Master training in the domain.

The proposed repository, in addition to a novel structuration, incorporates topics which are not specified in existing repositories: concrete approaches for strategic alignment of IS, methods and techniques for designing and implementing software, prerequisites in basic disciplines (computer science, management science, discrete mathematics), interpersonal competencies.

In accordance with principle 4, we propose to separate the general competencies into two parts: the superior competencies which report directly on the activities of the trades in the domain and the primary competencies which serve as a basis for the previous ones. This gives five superior general competencies that correspond to a breakdown of the domain into major processes (see Table 1).

There are also five general primary competencies (see Table 1). The breakdown globally respects the training disciplines. Competencies I, G, M, which refer respectively to computer science, management science and mathematics, bring together the knowledge and competencies of these disciplines which are useful or necessary for the acquisition of superior competencies. They are located at levels 2, 3, 4 of the BLOOM classification. $\mathrm{CP}$ competency brings together the interpersonal competencies required for the activities of trades. These competencies are broad and the prerequisite relationship makes it possible to specify those which relate more specifically to each case. IE competency corresponds to innovation, R\&D and entrepreneurship activities. 
Table 1. Ten general competencies for the domain of information systems

\begin{tabular}{|l|l|}
\hline Domain & Information systems design and implementation \\
\hline \multirow{4}{*}{$\begin{array}{l}\text { General superior } \\
\text { competencies }\end{array}$} & PS-Managing the information system at the strategic level \\
\cline { 2 - 2 } & PO-Managing the information system at the operational level \\
\cline { 2 - 2 } & CD-Designing and implementing computer applications and systems \\
\cline { 2 - 3 } General primary & FO-Maintaining in operation IT infrastructures and implementing their evolutions \\
\cline { 2 - 3 } competencies & SS-Implementing an information system in a specific sector \\
\cline { 2 - 2 } & G-Choosing and using computer science models, methods and techniques \\
\cline { 2 - 2 } & M-Implementing mathematical models to evaluate or optimize a product, a process, a service \\
\cline { 2 - 2 } & CP-Assessing and improving interpersonal competencies \\
\cline { 2 - 2 } & IE-Developing innovation, research and entrepreneurship projects \\
\hline
\end{tabular}

These primary competencies can be considered as global prerequisites. They could be the subject of a pre-master training. But it is not necessary to master all primary competencies before superior ones. Some may correspond to advanced topics whose mastery may be deferred. The prerequisite can be used to organize the training chronology. In addition, a training is not intended to integrate all the competencies of the repository. There is therefore a certain flexibility to compose an academic or a professional course from the repository.

In order to save space, we explicit only the levels "main" and "specific" for the 5 general superior competencies. Each one is described through a table. In a table, prerequisites are installed by using labels associated to the first three levels. We give textual descriptions for the 5 general primary competencies. For these 10 general competencies, we indicate the main correspondences, when they exist, with the e-CF and MSIS repositories. We also present an example to illustrate elementary competencies. The complete repository can be viewed from the URL: http://miage.univ-lyon1.fr/referentiel-anglais/.

The PS competency corresponds to the strategic steering activities of the IS which are carried out in close association by actors of general management, business lines and IT department. It mainly concerns the elaboration of a map of the existing IS at all levels (business processes, functions, applications, infrastructures), the detection and the characterization of problems or any wish for change and evolution, the choice of a solution, the initialization of the implementation of this solution through a strategic project. This block covers and extends competencies A1, A3, A4, D10, E1, E2, E3, E5, E7 of e-CF. There are correspondences with the "Enterprise Architecture", "IS Strategy and Governance" and "Business Continuity and Information Assurance" areas of the MSIS repository.

Table 2

PS-Managing the information system at the strategic level

\begin{tabular}{|c|c|c|}
\hline Main competencies & Specific competencies & Prerequisite \\
\hline \multicolumn{3}{|l|}{ Car-Elaborating a global IS map } \\
\hline \multirow{3}{*}{$\begin{array}{l}\text { Fes-Formalizing a solution for a strategic } \\
\text { evolution }\end{array}$} & a-Characterizing a strategic need in its context & G-Str, G-Dof, CD-Sbe \\
\hline & $\begin{array}{l}\text { b-Studying potential solutions to meet a strategic need } \\
\text { and choose a solution }\end{array}$ & G, PO-Msi-d, CP-Car-f \\
\hline & $\begin{array}{l}\text { c-Developing a macroscopic formalization of a solution } \\
\text { to meet a strategic need }\end{array}$ & CD-Mod, PS-Car \\
\hline \multirow{4}{*}{$\begin{array}{l}\text { Oes-Studying opportunity of typical solutions } \\
\text { of strategic evolution }\end{array}$} & a-Using an ERP software & G \\
\hline & b-Unifying separate information systems & G \\
\hline & c-Outsourcing activities and services & G \\
\hline & d-Using a decisional system & G \\
\hline Gps-Managing portfolio of strategic projects & & $\begin{array}{l}\text { M-Rop-a, M-Gra, G-Str, } \\
\text { CP-Car }\end{array}$ \\
\hline $\begin{array}{l}\text { Gcc-Managing strategic change and ensure the } \\
\text { continuity of business processes }\end{array}$ & & G \\
\hline \multirow[t]{3}{*}{ Gco-Managing knowledge } & $\begin{array}{l}\text { a-Identifying forms of knowledge and issues of } \\
\text { knowledge management in organizations }\end{array}$ & G \\
\hline & b-Formalizing knowledge & I-Bdd, M-Log \\
\hline & c-Implementing a knowledge management system & I-Bdd \\
\hline Gdd-Organizing data governance & & I-Bdd \\
\hline
\end{tabular}


The PO competency corresponds to operational steering activities which are mainly carried out by actors of the Information Systems Department: determining solutions for the evolution of applications and infrastructures, managing project, managing quality and security, managing resource. This block corresponds to competencies D1, D2, D8, E2, E6, E7, E8, E9 of e-CF. There are connections with the MSIS repository for project management, quality, security, IS management.

\section{Table 3}

\begin{tabular}{|c|c|c|}
\hline \multicolumn{3}{|c|}{ PO-Managing the information system at the operational level } \\
\hline Main competencies & Specific competencies & Prerequisite \\
\hline \multirow[t]{2}{*}{$\begin{array}{l}\text { Eai-Managing requests for evolution of } \\
\text { applications and infrastructures }\end{array}$} & $\begin{array}{l}\text { a-Designing a solution for a request for changes in } \\
\text { applications and infrastructures }\end{array}$ & PO-Msi-d \\
\hline & $\begin{array}{l}\text { b-Managing the portfolio of application projects and } \\
\text { infrastructure projects }\end{array}$ & $\begin{array}{l}\text { M-Rop-a, M-Gra, } \\
\text { CP-Car }\end{array}$ \\
\hline \multirow[t]{2}{*}{$\begin{array}{l}\text { Sai-Studying typical solutions for evolution of } \\
\text { applications and infrastructures }\end{array}$} & $\begin{array}{l}\text { a-Explaining the iso-functional reengineering of an } \\
\text { application }\end{array}$ & \\
\hline & b-Explaining migration of infrastructures & \\
\hline \multirow[t]{7}{*}{ Ppr-Managing a project } & a-Analyzing the objectives and constraints of a project & PO-Msi-d \\
\hline & b-Breaking down a project into tasks & \\
\hline & c-Choosing a project management methodology & \\
\hline & d-Elaborating and watching a schedule for a project & M-Gra \\
\hline & e-Managing the risks of a project & \\
\hline & f-Coordinating the project team & CP-Car \\
\hline & g-Communicating with the client of a project & CP-Car \\
\hline \multirow[t]{3}{*}{ Qua-Organizing IS quality } & a-Identifying potential approaches for IS quality & \\
\hline & b-Defining an IS quality policy & \\
\hline & c-Controlling IS quality & G-Aud \\
\hline \multirow[t]{2}{*}{ Ssi-Organizing IS security } & $\begin{array}{l}\text { a-Defining an IS security policy and the terms of its } \\
\text { application }\end{array}$ & $\begin{array}{l}\text { I-Sec, FO-Gin-d, } \\
\text { G-Aud }\end{array}$ \\
\hline & $\begin{array}{l}\text { b-Analyzing incident history and updating IS security } \\
\text { policy }\end{array}$ & M-Sta-a, G-Aud \\
\hline \multirow[t]{4}{*}{ Msi-Managing the IS } & a-Managing human resources & G-Dof \\
\hline & b-Managing financial resources & G-Dof, G-Out \\
\hline & c-Defining contract policy & G-Jur \\
\hline & d-Organizing and supervising IS activities & G-Out, G-Aud \\
\hline
\end{tabular}

The CD competency refers to all activities related to the design and production of IT solutions. It also relates to know-how for the implementation of specific systems and applications relating to decision-making, multimedia and mobility. The prerequisites come from competencies inside this block or inside blocks I, M, G. Correspondences exist with competencies B1 to B6, A6 and D11 of the e-CF. This block also corresponds to the "System Development and Deployment" area of the MSIS repository.

Table 4

\section{CD-Designing and implementing solutions}

\begin{tabular}{|l|l|l|}
\hline CD-Designing and implementing solutions \\
\hline Main competencies & Specific competencies & Prerequisite \\
\hline Mod-Using modeling languages & a-Modeling with the Entities Associations (EA) model & \\
\cline { 2 - 3 } & b-Modeling with UML & \\
\cline { 2 - 3 } & c-Modeling with BPM & \\
\cline { 2 - 3 } & d-Identifying other modeling languages & CP-Car-a/d \\
\cline { 2 - 3 } & e-Using meta modeling & \\
\hline \multirow{5}{*}{ Sbe-Identifying and specifying requirements } & a-Acquiring and formalizing requirements & \\
\cline { 2 - 3 } & b-Using formal specification of requirements & CD-Mod, CD-Sbe \\
\hline Mco-Using design and development methods & a-Choosing a development process & CD-Mod, M-Pet, \\
\cline { 2 - 3 } & b-Choosing a design and development method \\
\cline { 2 - 3 } $\begin{array}{l}\text { Sdc-Developing conceptual diagrams for data } \\
\text { and behavior }\end{array}$ & c-Applying a design and development method \\
\cline { 2 - 3 } & a-Developing a conceptual diagram for data & b-Developing a conceptual diagram for behavior \\
\hline $\begin{array}{l}\text { Alo-Implementing software architecture with } \\
\text { design patterns, architectural patterns and } \\
\text { frameworks }\end{array}$ & & CD-Mod-b \\
\hline
\end{tabular}




\begin{tabular}{|c|c|c|}
\hline \multirow{3}{*}{$\begin{array}{l}\text { Ihm-Designing and developing human-machine } \\
\text { interfaces (HMI) }\end{array}$} & a-Describing the elements which compose an interface & \\
\hline & b-Designing an interface & CP-Car-a/d \\
\hline & c-Implementing an interface & CD-Alo \\
\hline \multirow{5}{*}{$\begin{array}{l}\text { Pas-Organizing the programming of an } \\
\text { application or a system }\end{array}$} & a-Using the principles of software quality assurance & \\
\hline & b-Using automatic code generation & \\
\hline & c-Using good practices for manual coding & \\
\hline & d-Documenting the code & \\
\hline & e-Using test-driven development & CD-Tas \\
\hline \multirow{3}{*}{$\begin{array}{l}\text { Tas-Organizing dynamic tests of an application } \\
\text { or system }\end{array}$} & a-Explaining the different types of dynamic tests & \\
\hline & b-Elaborating dynamic test plans & \\
\hline & c-Automating dynamic testing & \\
\hline \multirow[t]{3}{*}{ Moa-Managing the installation of an application } & a-Managing the configurations of an application & \\
\hline & $\begin{array}{l}\text { b-Managing the deployment of an application or a } \\
\text { software package }\end{array}$ & \\
\hline & c-Managing the maintenance of an application & \\
\hline \multirow{5}{*}{$\begin{array}{l}\text { Dsd-Developing decisional applications and } \\
\text { systems }\end{array}$} & a-Collecting decision-making needs & CD-Sbe \\
\hline & b-Implementing decisional data structures & I-Bdd \\
\hline & c-Using an ETL to integrate data & \\
\hline & d-Using OLAP and reporting tools & \\
\hline & $\mathrm{e}-$ Using data mining and $\mathrm{Al}$ to solve decision problems & M-Dat, M-Ina, M-Sta \\
\hline $\begin{array}{l}\text { Dmm-Developing multimedia applications and } \\
\text { systems }\end{array}$ & & $\begin{array}{l}\text { CD-Ihm } \\
\text { CD-Alo }\end{array}$ \\
\hline $\begin{array}{l}\text { Dmo-Developing mobile applications and } \\
\text { systems }\end{array}$ & & $\begin{array}{l}\text { I-Sys-e, CD-Ihm, } \\
\text { CD-Alo }\end{array}$ \\
\hline Erp-Installing an ERP software & & $\begin{array}{l}\text { G-Dof, I-Sys, CD- } \\
\text { Mod, CD-Moa }\end{array}$ \\
\hline
\end{tabular}

The FO competency brings together the activities which ensure the proper functioning of the hardware and software infrastructures and which implement the changes decided at the PS and / or PO level. The prerequisites are mainly in computer science. In the e-CF, we can note a correspondence with D10. There are correspondences with the MSIS repository for all the competencies in this block.

Table 5

\section{FO- Maintaining the proper functioning of IT infrastructures and implementing their evolutions}

\begin{tabular}{|l|l|l|}
\hline Main competencies & Specific competencies & Prerequisite \\
\hline \multirow{3}{*}{$\begin{array}{l}\text { Gin-Managing hardware and software } \\
\text { infrastructures }\end{array}$} & a-Managing systems, networks, services & I-Sys, G-Aud \\
\cline { 2 - 3 } & b-Managing maintenance of infrastructure & I-Sys \\
\cline { 2 - 3 } & c-Optimizing performances of infrastructure & I-Sys, M-Sta \\
\cline { 2 - 3 } & d-Implementing infrastructure security & I-Sec, CP-Car-a, IE-Vei, \\
\cline { 2 - 3 } & e-Organizing infrastructure service continuity & I-Sys \\
\cline { 2 - 3 } & f-Integrating a new hardware or software component & I-Sys \\
\hline Gap-Managing applications & G-Dof, I-Sys & I-Sys, I-Bdd, CP-Car-j \\
\hline Gdo-Managing data & a-Administrating DBMS and data bases & I-Sys, I-Bdd \\
\cline { 2 - 3 } & b-Administrating data & \\
\hline
\end{tabular}

The SS competency corresponds to the implementation of an IS in a specific sector. Certain sectors, such as health for example, indeed require adapted approaches. A main competency is introduced for each sector. We propose, here, specific competencies for the health sector. It is essentially about knowing the structure and functioning of the health system and identifying the potentials that a digital information system can provide. 
Table 6

\begin{tabular}{|l|l|l|}
\hline SS-Implementing an Information System in a specific sector \\
\hline Main competencies & Specific competencies & Prerequisite \\
\hline $\begin{array}{l}\text { San-Implementing an Information System in } \\
\text { the health sector }\end{array}$ & $\begin{array}{l}\text { a-Explaining organization and operation of the health } \\
\text { system }\end{array}$ & \\
\cline { 2 - 3 } & b-Explaining challenges of the personal health record & \\
\cline { 2 - 3 } & c-Explaining operation of care networks & \\
\cline { 2 - 3 } & d-Explaining organization and operation of the hospital & G-Dof \\
\cline { 2 - 3 } & e-Explaining data processing in epidemiology & \\
\hline & f-Explaining assessment of medical practices & M-Sta \\
\cline { 2 - 3 } & $\begin{array}{l}\text { g-Explaining standards and classifications used for } \\
\text { medical knowledge }\end{array}$ & PS-Gco \\
\cline { 2 - 3 } & h-Explaining the major uses of ICT in health & I-Bdd, I-lot, M-Sta, \\
& & M-Dat, M-Ina \\
\hline
\end{tabular}

Other sectors can be considered: finance, transport and distribution, tourism and leisure, telecommunications, public sector and e-government. The MSIS repository expresses competencies for several specific sectors.

These 5 general superior competencies are mainly found at competency levels 3, 4, 5 of the BLOOM classification. Remember that we are aiming for a level of ability corresponding to an early career in the various trades of the domain.

The I competency aims at a deep knowledge of the foundations of IT and its foreseeable evolution, the aptitude to develop software in any type of language, the aptitude to install and operate the different computer systems which a company can use to support its information system. A good mastery of these competencies is necessary for the five superior general competencies and more particularly for the CD and FO competencies. The e-CF does not structure this type of competencies. It includes references to data management and programming. The MSIS repository structures competencies relating to data management, the management of IT systems and networks, the management of IT security and risks.

The $\mathrm{G}$ competency is about understanding the models, reasoning and tools used by business managers. This block mainly brings together knowledge relating to the economic and legal environment of companies, the business strategy, the operation of different units, the business processes, the control via accounting mechanisms. It also includes know-how relating to internal audit. This knowledge and know-how are essential for the proper implementation of activities in the PS, PO, CD blocks. The e-CF and MSIS repositories do not directly structure competencies about these topics. The e-CF repository, on the other hand, defines competencies relating to the functions of buying and selling products and services in the IS domain (D4, D5, D6, D7)

The $\mathrm{M}$ competency aims, on the one hand, at understanding the main theories of discrete mathematics and artificial intelligence, their constraints and limits, and, on the other hand, the ability to reuse and improve algorithms for analysis and optimization through languages and software packages. These competencies are useful and necessary for data processing, development of assessment models and decision support at the level of PS, PO, CD blocks. This type of competencies is partially expressed in the MSIS standard.

The CP competency brings together interpersonal competencies. Many interpersonal competencies have been characterized and classified (Scouarnec, 2019; Bonnstetter \& Brooks, 2003; Oecd, 2014). The objective here is to specify those which relate more specifically to the trades in the domain. For each of them, it is a question of understanding its effects, having its level of ability assessed or self-assessed, identifying ways of improvement and implementing them. The prerequisites, established in the other blocks, make it possible to specify the interpersonal competencies which are more especially expected to carry out a particular activity. This block also offers competencies to strengthen his professionalism and manage his professional career. Interpersonal competencies are not explicitly present in the e-CF. Some are developed in the MSIS repository. The FNEGE framework (Scouarnec, 2019), positioned on general management and business management, is organized around this type of competencies.

The IE competency brings together competencies relating to technology watch, innovation, R\&D, entrepreneurship. The IS domain is very favorable for the development of new scientific and technological advances and the acquisition of this type of competencies should be recommended. The e-CF repository incorporates a technology watch competency (A7) and an innovation competency (A9). The MSIS repository includes competencies relating to innovation and entrepreneurship. 
We now give some comments about elementary competencies. Remember that an elementary competency is not intended to be broken down. Through its specification, any industrial or academic tutor must be able to interpret without ambiguity the knowledge, know-how and interpersonal competencies that it covers. In particular, he/she may deduct the teaching activities to be implemented in order to acquire the competency and the assessments to be carried out to verify that the competency is well mastered. For illustrating, we give below the elementary competencies that we propose for the specific competency "Administrating DBMS and databases" of the main competency "Managing data" in the FO block. We have highlighted teaching activities enabling to master these elementary competencies. Assessment can be easily deduced: MCQ, exercises, analysis report of a case, analysis report about an experimentation, observation in simulated conditions, etc. These types of teaching activities and assessments are easily practicable in face-to-face configurations. In the field of ICT, there are now various solutions that allow them to be reproduced remotely.

Table 7. Example of elementary competencies and teaching activities

\begin{tabular}{|c|c|}
\hline \multicolumn{2}{|c|}{ Specific competency: a-Administrating DBMS and databases } \\
\hline Elementary competencies & Teaching activities \\
\hline - Installing a DBMS & $\begin{array}{l}\text { Explaining the principles of the operation and the variants of the implementation } \\
\text { process according to the characteristics of the server and the DBMS. } \\
\text { Illustrating the operation through an experiment. } \\
\text { Asking the apprentice to do the operation. }\end{array}$ \\
\hline - Performing version upgrades of a DBMS & Idem \\
\hline $\begin{array}{l}\text { - Administrating databases (security, access } \\
\text { rights, storage optimization, request } \\
\text { optimization, backup, restoration, ...) }\end{array}$ & $\begin{array}{l}\text { Idem } \\
\text { (for each operation) }\end{array}$ \\
\hline $\begin{array}{l}\text { - Identifying and correcting problems or } \\
\text { incidents related to DB and DBMS }\end{array}$ & $\begin{array}{l}\text { Idem } \\
\text { (for each type of incident) }\end{array}$ \\
\hline - Performing a technology watch on DBMS & Explaining important points to watch and potential sources to consult. \\
\hline - Assisting data base users & $\begin{array}{l}\text { Explaining the difficulties that users generally encounter. } \\
\text { Explaining the behavior to adopt towards each type of user and each type of } \\
\text { assistance process. } \\
\text { Accompanying the apprentice in real situations. }\end{array}$ \\
\hline - Contributing to the choice of a DBMS & $\begin{array}{l}\text { Explaining the parameters to take into account. } \\
\text { Explaining how to elaborate an argumentation according to the constraints of the } \\
\text { choice. } \\
\text { Explaining the behavior to adopt during a meeting organized for the choice. }\end{array}$ \\
\hline
\end{tabular}

\section{EVALUATION}

In this section, we give elements for evaluating our proposals.

Evaluation of the structuring approach

The proposed approach is based on five principles and makes it possible to organize competencies in the form of composition hierarchies with four levels of abstraction: general, main, specific, elementary. The general level corresponds to the notion of competency block. At all levels, competencies are specified in the same way using action verbs that may relate to the classification of BLOOM. These verbs make it possible to clearly set the objectives. At the elementary level, they allow to induce the type of assessments to be carried out to measure their achievement. The measures can then be propagated by aggregation in the upper levels. In addition, it is recommended to instantiate prerequisites between competencies. This kind of structuration is general and can be considered for building a competency repository in any domain.

Thus organized, a competency repository provides the facilities we aimed at:

- Easily searching for a competency. The repository is similar to a semantic map which can be browsed from general competency to more detailed ones (main, specific, elementary).

- Easily inserting a new competency. The semantic map makes it possible to identify the most appropriate positioning for inserting a new competency (main, specific, elementary).

- Easily developing initial and vocational training. The issue is to derive a specific competency repository for a certification or a training. It is possible to proceed from objectives or from trades or roles. Each hierarchical level defines a learning objective. One can select one or more objectives and assemble the 
corresponding competencies by attaching all the lower level competencies linked by composition and prerequisites. Filtering can be carried out. The resulting repository has as many blocks as separate hierarchies in the assembly. We can do the same by trades: the competencies-to-trades correspondence brings together all the competencies corresponding to the selected trades.

- Drawing up a competency assessment. Anyone can identify the competency included in its profile and can perform a self-assessment (using the elementary competencies specifications) to draw up a competency assessment in relation to the area covered by the repository.

- Easily finding training courses that meet a learning objective. Suppose that a set E of existing training courses have been previously indexed by competencies, searching for courses that satisfy a learning objective identified by $\mathrm{X}$ then consists in searching for the training of $\mathrm{E}$ indexed by $\mathrm{X}$.

Evaluation of the competency repository in the domain of information systems

The repository we propose is elaborated from an initial repository designed by the French network of MIAGE Masters. We first structured the initial repository according to the principles of the proposed approach. The new repository includes 10 composition hierarchies (therefore 10 competency blocks) and a significant part of the existing specifications has been recovered. We then suggested extensions. In this new repository, we find, not surprisingly, most of the competencies offered by the repositories in the domain and in particular those of the e-CF and MSIS repositories. However, this repository has several particularities. First, it distinguishes superior competencies which correspond directly to the activities of the trades in the domain and primary competencies which serve as the basis for the previous ones. The latter bring together knowledge and competencies from the three basic disciplines of computer science, management science and discrete mathematics. Superior competencies are directly based on this type of knowledge and know-how. The prerequisites make it possible to express the most significant dependencies. The importance of these primary competencies will increase in the future as information systems evolve towards increased technicality, closer coupling with business processes, higher requirements in terms of data analysis and assistance to decision processes. Then, the "Designing and developing applications and systems" block was the subject of various enhancements to cover the ever widening range of development methods and technologies. A majority of students graduating in information system begin their professional career with activities corresponding to this block and it is necessary to take into account new approaches. In addition, we separated strategic management of the information system from operational management because they involve different actors. The two corresponding blocks have been enriched with competencies relating to design and implementation of typical solutions for the evolution and adaptation of an information system. Finally, we paid a particular attention to the block "Developing interpersonal competencies and professionalism". Interpersonal competencies (i.e. soft skills) have become essential in all trades in the domain. The recommendation that is made is that an individual be able, not only to identify the importance of an interpersonal competency relative to a trade, but also to assess his level of ability and to choose solutions to improve it.

Some competencies may depend on national contexts. This is particularly the case with corporate law. We have worded them in a neutral way. So, the proposed repository can be normally used in an international context.

\section{CONCLUSION}

In this paper we propose a general model to organize a competency repository and its instantiation in the domain of information systems. Numerous competency repositories have been suggested in different areas and surprisingly no proposal has been made to structure them. Our model is general and can be used to structure any type of repository. Such a proposal constitutes an effective way to facilitate understanding by users and maintenance by designers. In the domain of information systems, several competency repositories have been proposed. Our suggestion integrates the main points of these repositories and introduces many other points, in particular in terms of interpersonal competencies. It can be used both to guide the development of training and to assess individual competencies. We are implementing it in the context of the French network of MIAGE Masters. It is used in particular to help in the development of distance learning modules. 


\section{ACKNOWLEDGEMENT}

The authors would like to thank M. Gilles DESSAGNE, Head of the Urban Planning Division of IS at SNCF, for fruitful discussions. They want also to thank the French ANR (Agence Nationale de la Recherche) who funded this work.

\section{REFERENCES}

Acm. (2016). Computer Engineering Curricula. https://www.acm.org/binaries/content/assets/education/ce2016-finalreport.pdf

Anap. (2020). Référentiel de compétences en système d'information. Retrieved from http://ressources.anap.fr/ressourceshumaines/publication/196

Bloom, B. S. (1956). Taxonomy of educational objectives: the classification of educational goals, Handbook 1: Cognitive domain. White Plains, N.Y., Longman.

Bonnstetter, B.J. \& Brooks, B. (2003). List of soft skill competencies with description, Nielson Group. Retrieved from http://www.nielsongroup.com/articles/list_of_competencies.pdf

Cen. (2018). European ICT Professional Role Profiles built on the e-CF. Retrieved from www.ecompetences.eu/ictprofessional-profiles/

Churches, A. (2008). Bloom's taxonomy blooms digitally, Tech \& Learning, 2008, vol. 1, p. 1-6.

Cigref. (2018). Nomenclature CIGREF des métiers du système d'information, Club Informatique des Grandes Entreprises Françaises. Retrieved from www.cigref.fr/wp/wp-content/uploads/2018/07/Cigref-Nomenclature-RH-MetiersCompetences-2018_v2.pdf

e-CF. (2019). European e-Competence Framework. Retrieved from www.ecompetences.eu

Embo, M., Driessen, E., Valcke, M., \& Van der Vleuten, C. P. (2015). Integrating learning assessment and supervision in a competency framework for clinical workplace education. Nurse Education Today, 35(2), 341-346.

Kennedy, D. (2006). Writing and using learning outcomes: a practical guide, University College Cork.

Lundqvist, K. O., Baker, K., \& Williams, S. (2008). An ontological approach to competency management.

Oecd. (2014). Competency framework. Retrieved from www.oecd.org/careers/competency_framework_en.pdf

Opiiec. (2018). Référentiels métiers de la branche du numérique. Retrieved from www.referentiels-metiers.opiiec.fr/

Osters, S., \& Tiu, F. S. (2008). Writing measurable learning outcomes. In 3rd Annual Texas A\&M Assessment Conference.

O*NET On Line. (2020). Organization of Data in the O*NET Database and O*NET Online. Retrieved from https://www.onetonline.org/.

Paquette, G. (2007). An Ontology and a Software Framework for Competency Modeling and Management, Educational Technology \& Society, 10(3), 1-21.

Sastre-Fullana, P., De Pedro-Gómez, J. E., Bennasar-Veny, M., Serrano-Gallardo, P., \& Morales-Asencio, J. M. (2014). Competency frameworks for advanced practice nursing: a literature review. International nursing review, 61(4), 534-542.

Schmidt, A., \& Kunzmann, C. (2006). Towards a human resource development ontology for combining competence management and technology-enhanced workplace learning. In : OTM Confederated International Conferences "On the Move to Meaningful Internet Systems". Springer, Berlin, Heidelberg, p. 1078-1087.

Scouarnec, A., \& all. (2019). Les compétences de demain - « Management et Gestion des Affaires », Fnege. Retrieved from www.fnege.org/publications/referentiel-prospectif-des-competences-management-gestion-des-affaires.

Sfia. (2018). The global skills and competency framework for a digital world, version 7. Retrieved from https://www.sfia-online.org/en.

Topi, H. \& all. (2016). MSIS 2016 Global Competency Model for Graduate Degree Programs in Information Systems. Retrieved from www.acm.org/binaries/content/assets/education/msis2016.pdf.

Vandeweerd, J. M., Cambier, C., Romainville, M., Perrenoud, P., Desbrosse, F., Dugdale, A., \& Gustin, P. (2014). Competency frameworks: which format for which target?. Journal of veterinary medical education, 41(1), 27-36.

Whitehead, C. R., \& Kuper, A. (2015). Competency-based training for physicians: are we doing no harm? Cmaj, 187(4), E128-E129. 